\title{
Bioinformatics analysis of the CDK2 functions in neuroblastoma
}

\author{
LIJUAN BO $^{1 *},{\text { BO } \text { WEI }^{2 *}, \text { ZHANFENG WANG }^{2}, \text { DALIANG KONG }^{3}, \text { ZHENG GAO }^{2} \text { and ZHUANG MIAO }}^{2}$ \\ Departments of ${ }^{1}$ Infections, ${ }^{2}$ Neurosurgery and ${ }^{3}$ Orthopaedics, China-Japan Union Hospital of Jilin University, \\ Changchun, Jilin 130033, P.R. China
}

Received December 20, 2016; Accepted November 14, 2017

DOI: $10.3892 / \mathrm{mmr} .2017 .8368$

\begin{abstract}
The present study aimed to elucidate the potential mechanism of cyclin-dependent kinase 2 (CDK2) in neuroblastoma progression and to identify the candidate genes associated with neuroblastoma with CDK2 silencing. The microarray data of GSE16480 were obtained from the gene expression omnibus database. This dataset contained 15 samples: Neuroblastoma cell line IMR32 transfected with CDK2 shRNA at $0,8,24,48$ and $72 \mathrm{~h}$ (n=3 per group; total=15). Significant clusters associated with differentially expressed genes (DEGs) were identified using fuzzy C-Means algorithm in the Mfuzz package. Gene ontology and pathway enrichment analysis of DEGs in each cluster were performed, and a protein-protein interaction (PPI) network was constructed. Additionally, functional annotation of DEGs in clusters was performed for the detection of transcription factors and tumor-associated genes. A total of 4 clusters with significant change tendency and 1,683 DEGs were identified. The hub nodes of the PPI network constructed by DEGs in Cluster 1, Cluster 2, Cluster 3 and Cluster 4 were MDM2 oncogene, E3 ubiquitin protein ligase (MDM2), cyclin-dependent kinase $1(C D K 1)$, proteasome (prosome, macropain) $26 \mathrm{~S}$ subunit, non-ATPase, 14 (PSMD14) and translocator protein $(18 \mathrm{kDa})(T S P O)$ respectively. These genes were significantly enriched in the p53 signaling pathway, cell cycle, proteasome and systemic lupus erythematosus pathways. $M D M 2, C D K 1$, PSMD14 and TSPO may be key target genes of CDK2. CDK2 may have key functions in neuroblastoma progression by regulating the expression of these genes.
\end{abstract}

\section{Introduction}

Neuroblastoma is an embryonal tumor that arises from the sympathetic nervous system, accounts for $\sim 15 \%$ of

Correspondence to: Dr Zhuang Miao, Department of Neurosurgery, China-Japan Union Hospital of Jilin University, 126 Xiantai Street, Changchun, Jilin 130033, P.R. China

E-mail: miaozhuang99@163.com

*Contributed equally

Key words: neuroblastoma, cyclin-dependent kinase 2, differentially expressed genes, pathways analysis, protein-protein interaction childhood cancer mortality $(1,2)$. Despite intensive myeloablative chemotherapy, survival rates for neuroblastoma have not substantively improved; relapse is common and frequently leads to mortality $(3,4)$. Like most human cancers, this childhood cancer can be inherited; however, the genetic aetiology remains to be elucidated (3). Therefore, an improved understanding of the genetics and biology of neuroblastoma may contribute to further cancer therapies.

In terms of genetics, neuroblastoma tumors from patients with aggressive phenotypes often exhibit significant MYCN proto-oncogene, bHLH transcription factor (MYCN) amplification and are strongly associated with a poor prognosis (5). MYCN, a member of MYC proto-oncogene family, functions as a transcriptional factor, which controls cell growth and proliferation and thus has an important role in driving tumorigenesis of neuroblastoma cells $(6,7)$. Additionally, the overexpression of $M Y C$ genes in non- $M Y C$-amplified cells may induce apoptosis (8). A previous study by Molenaar et al (9) confirmed that inactivation of cyclin-dependent kinase 2 (CDK2) was synthetically lethal to neuroblastoma cells with MYCN-amplification and overexpression (9). The CDK2 gene encodes a protein that is member of serine/threonine protein kinase family that is involved in cell cycle regulation (10). Additionally, $C D K 2$ has been demonstrated to regulate the progression through the cell cycle (11). A previous study also has determined that the targeting of aberrant cell cycle checkpoints in cancer cells may inhibit tumor growth and induce cell death (12). CDK2 is a vital regulator of S-phase progression and is deemed to be an anticancer drug target $(9,13)$. Additionally, CDK2 inhibitors may act as potential $M Y C N$-selective cancer therapeutics in the treatment of neuroblastoma (9). However, the molecular mechanism of CDK2 in the genesis of childhood cancer neuroblastoma remains to be fully elucidated.

In a previous study, microarray data from GSE16480 was used for identification of the upregulated genes following CDK2 silencing. The findings revealed that these upregulated genes were target genes of $\mathrm{p} 53$, and silencing of $\mathrm{p} 53$ protected the cells from MYCN-driven apoptosis (9). However, to the best of our knowledge, there was no systematic and comprehensive analysis for this expression profile. The present study downloaded the microarray data of GSE16480 and then identified significant clusters associated with differentially expressed genes (DEGs) following CDK2 silencing. Gene ontology (GO) and pathway enrichment analysis of DEGs in each cluster were performed, and protein-protein interaction 
(PPI) network was constructed. Additionally, a functional annotation of DEGs in the clusters was performed. The present study aimed to identify key genes and biological pathways underlying the progression of neuroblastoma with CDK2 silencing by means of comprehensive bioinformatics analysis to further elucidate the function of CDK2 in neuroblastoma progression and determine potential targets for future cancer therapies.

\section{Materials and methods}

Source of data. The microarray data GSE16480 was downloaded from Gene Expression Omnibus (GEO, http://www. ncbi.nlm.nih.gov/geo/) database based on the platform of GPL570 (Affymetrix Human Genome U133 Plus 2.0 Array), which was deposited by Molenaar et al (9). This dataset contained 15 samples: Neuroblastoma cell line IMR32 was transfected with CDK2 shRNA at 0, 8, 24, 48 and $72 \mathrm{~h}(\mathrm{n}=3$ per group; total=15)

Data preprocessing. Background correction, quartile normalization and probe summarization were performed to normalize the gene expression intensities obtained from the raw dataset using robust multi-array average algorithm (14), and the gene expression time-course matrix of samples was acquired.

Soft clustering analysis. Noise robust soft clustering of gene expression time-course data was implemented using the fuzzy C-Means algorithm (15) in the Mfuzz package $(15,16)$. The following parameters were set: Minimum Standard Deviation $=0.4$, score $=0.7$. This method may assign genes into several clusters according to the expression pattern of DEGs. Then, clusters with significant change tendency were screened for further analysis.

PPI network construction. The Search Tool for the Retrieval of Interacting Genes (STRING) database (17) is a database for the exploration and analysis of known and predicted protein interactions, including both experimental and predicted interaction information. The present study used the STRING online tool to analyze the PPIs of up and downregulated genes with required confidence (combined score) $>0.4$. The hub proteins were subsequently identified from the PPI network based on connectivity degree analysis.

GO and pathway enrichment analysis. GO (18) is widely used for the studies of large-scale genomic or transcriptomic data in function. Kyoto Encyclopedia of Genes and Genomes (KEGG) (19) is an online pathway database, which deals with genomes, enzymatic pathways and biological chemicals. The present study identified over-represented GO categories in biological processes and significant KEGG pathways of the DEGs in each cluster. The P-value of the default hypergeometric test of $>0.05$ was selected as the threshold.

Functional annotation of DEGs in each cluster. The tumor suppressor gene (TSGene) (20) database provides detailed annotation for each tumor suppressor gene (TSGs), such as transcription factors (TF) regulations. The tumor-associated gene (TAG) database (21) summarizes attributes for a specific entity associated with the TAGs.

Functional annotations of DEGs in clusters were performed for the detection of TFs and TAGs and both databases, TSGene and TAG database, were used to identify oncogenes and tumor suppressor genes.

\section{Results}

Soft clustering analysis. Soft clustering analysis of gene expression time-course data identified 4 clusters with significant change tendency (Fig. 1). Cluster 1 presented an increasing trend (Fig. 1A). Specifically, the expression levels of genes exhibited an increase from 0 to $8 \mathrm{~h}$; subsequently the levels increased significantly from 8 to $48 \mathrm{~h}$ and remained constant from 48 to $72 \mathrm{~h}$. It is of note that the change tendency of gene expression in Cluster 3 (Fig. 1C) at different time points is evidently opposite to those observed in Cluster 1. The expression levels of genes in Cluster 3 decreased slightly from 0 to $8 \mathrm{~h}$, subsequently the levels decreased significantly from 8 to $48 \mathrm{~h}$ and remained constant from 48 to $72 \mathrm{~h}$. In addition, the change tendency of gene expression in Cluster 2 (Fig. 1B) at different time points was evidently opposite to those observed in Cluster 4 (Fig. 1D). The expression levels of genes in Cluster 2 decreased from 0 to $24 \mathrm{~h}$ and subsequently decreased significantly from 24 to $72 \mathrm{~h}$, whereas in Cluster 4 this trend was reversed.

Additionally, DEGs with the same expression pattern as change tendency of clusters was screened. A total of 1,683 DEGs were identified, including 337 upregulated genes in Cluster 1, 649 downregulated genes in Cluster 2, 387 downregulated genes in Cluster 3, and 387 upregulated genes in Cluster 4.

PPI network construction. The PPI networks of DEGs in Cluster 1 (Fig. 2A), 2 (Fig. 2B), 3 (Fig. 2C) and 4 (Fig. 2D) included 86, 18,875, 239 and 109 interactions, respectively. Based on connectivity degree, the hub genes with the highest degrees in the four clusters were: MDM2 oncogene, E3 ubiquitin protein ligase (MDM2), cyclin-dependent kinase 1 $(C D K 1)$, proteasome (prosome, macropain) 26S subunit, non-ATPase, 14 (PSMD14), translocator protein (18 kDa) (TSPO), respectively (Table I).

GO and pathway enrichment analysis. The present study performed GO and KEGG pathway analysis for DEGs in 4 clusters. The over-represented GO terms of DEGs in Cluster 1, 2, 3 and 4 were response to DNA damage stimulus, cell cycle, antigen processing and presentation of peptide antigen via MHC class I, and cell surface receptor signaling pathway, respectively (Table II). The significantly enriched KEGG pathways of cluster genes in Cluster 1, 2, 3 and 4 were the p53 signaling pathway, cell cycle, proteasome, and systemic lupus erythematosus, respectively (Table III).

Functional annotation of DEGs in each cluster. As presented in Table IV the present study revealed that with increased time 5 TFs and 13 TAGs in Cluster 1 were upregulated, 17 TFs and 49 TAGs in Cluster 2 were downregulated, 3 TFs and 3 TAGs in Cluster 3 were downregulated, 3 TFs and 15 TAGs in Cluster 4 were upregulated. 

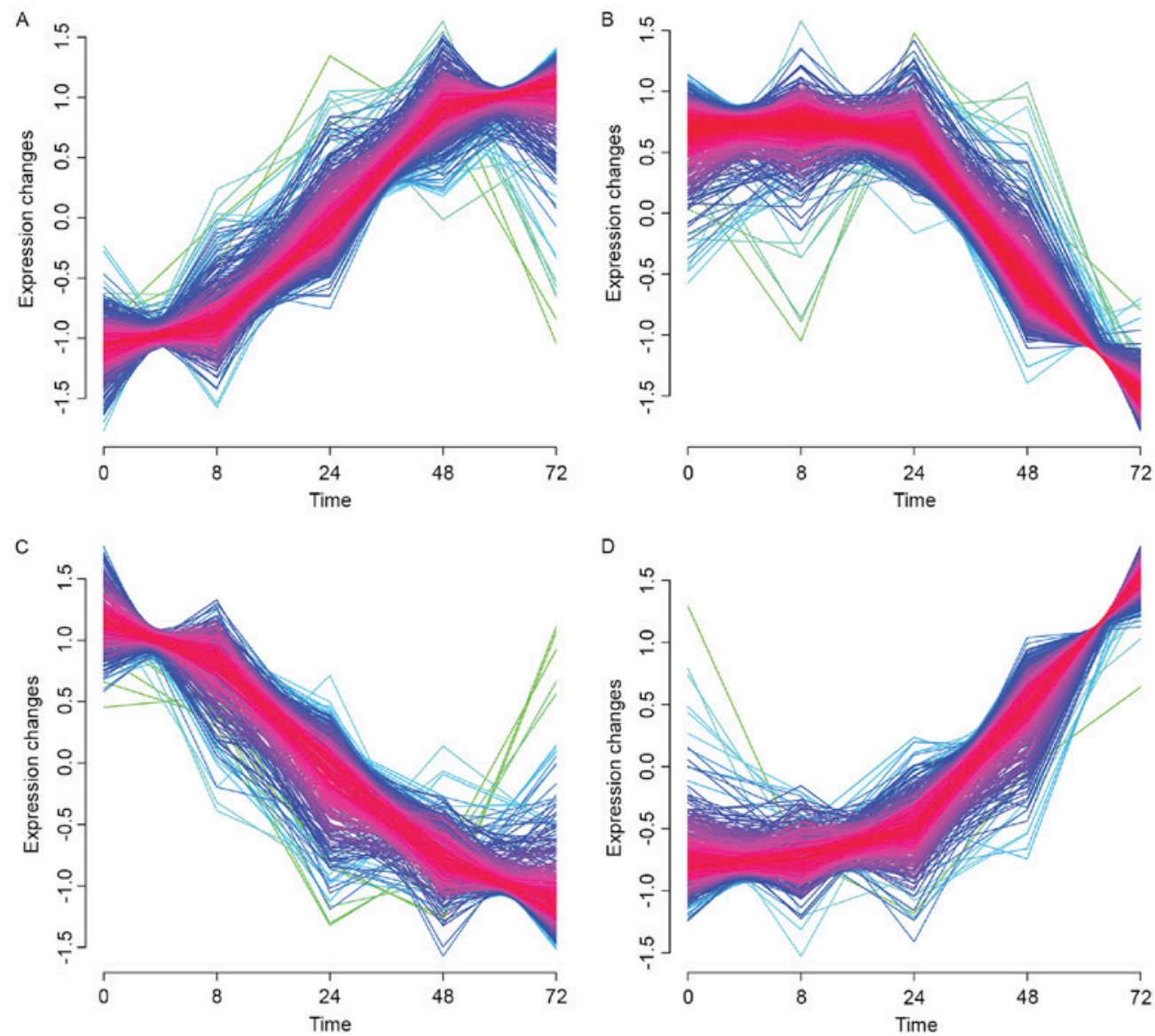

Figure 1. Clustering results of Cluster (A) 1, (B) 2, (C) 3 and (D) 4. Red shades indicate high membership values and green shades low membership values of genes.

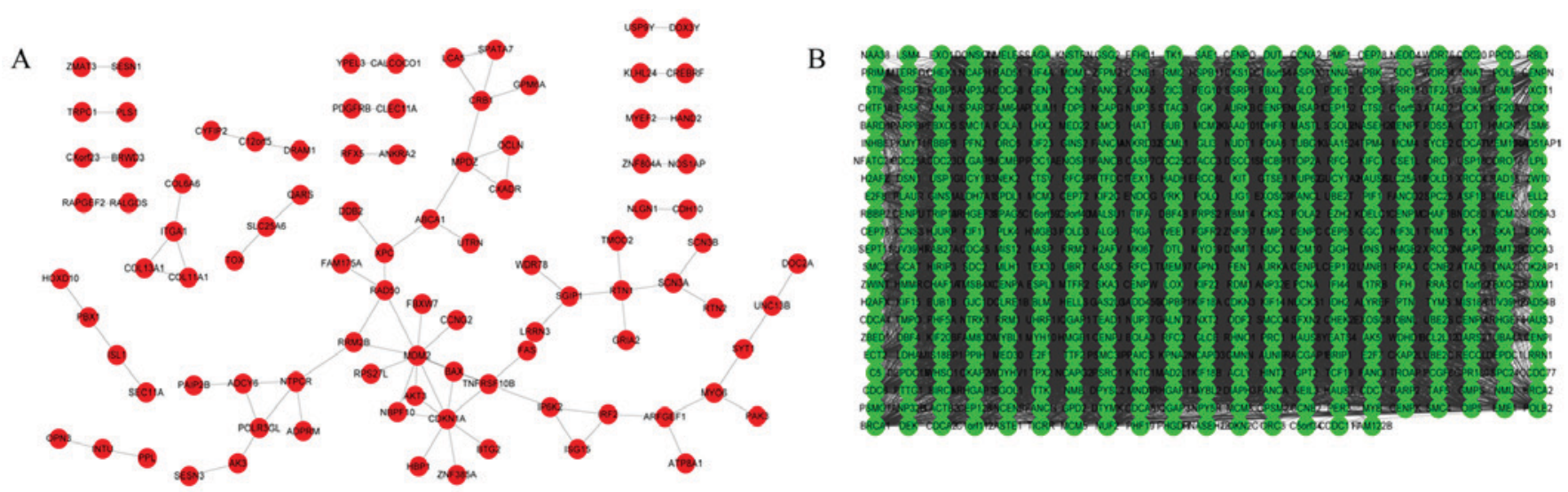

C

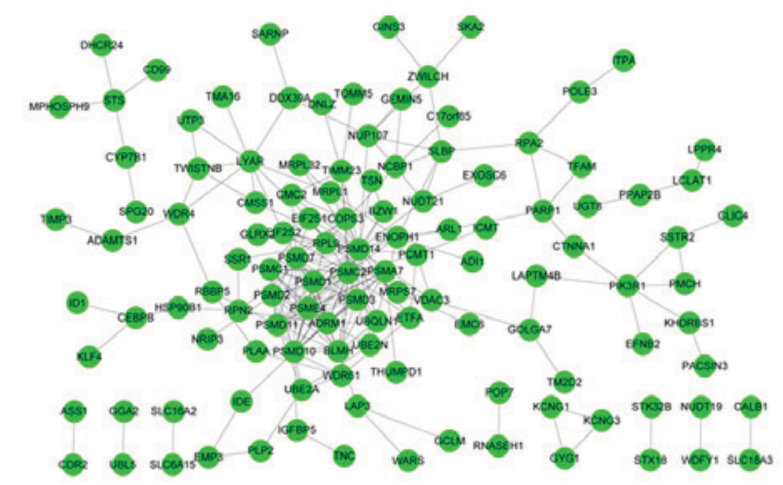

D

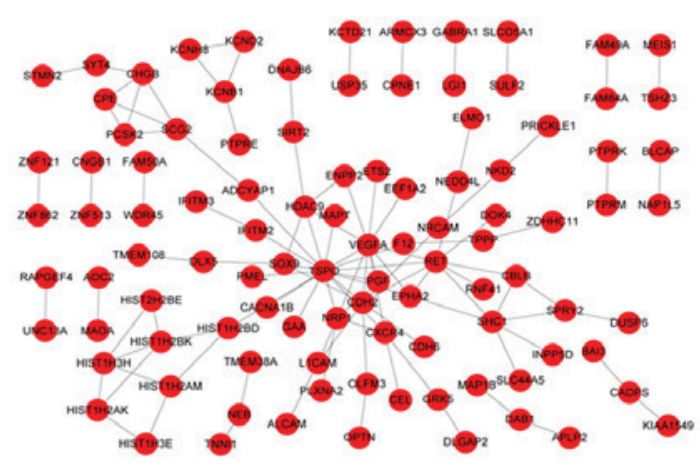

Figure 2. Protein-protein interaction networks of differentially expressed genes in Cluster (A) 1, (B) 2, (C) 3 and (D) 4. Red nodes indicate upregulated genes and green nodes indicate downregulated genes. The edges indicate interactions between these genes. 
Table I. Top 10 nodes in the protein-protein interaction network.

\section{A, Cluster 1}

\begin{tabular}{lc}
\hline Gene & Degree \\
\hline MDM2 & 10 \\
CDKN1A & 8 \\
TNFRSF10B & 5 \\
CRB1 & 4 \\
MPDZ & 4 \\
NTPCR & 4 \\
RAD50 & 4 \\
RTN1 & 4 \\
ABCA1 & 4 \\
ADCY6 & 3 \\
\hline
\end{tabular}

\section{B, Cluster 2}

\begin{tabular}{lc}
\hline Gene & Degree \\
\hline CDK1 & 253 \\
MAD2L1 & 251 \\
RFC4 & 248 \\
BUB1 & 241 \\
NCAPG & 239 \\
CCNA2 & 238 \\
CHEK1 & 236 \\
CCNB1 & 233 \\
NDC80 & 232 \\
PBK & 232 \\
\hline
\end{tabular}

\section{C, Cluster 3}

\section{Gene}

Degree

\section{PSMD14}

PSMC2

23

PSMD10

PSMD7

PSMC1

PSMD11

ADRM1

BLMH

PSMD3

PSMD1

\section{D, Cluster 4}

Gene

TSPO

VEGFA

RET

$\mathrm{CDH} 2$

$\mathrm{SHC} 1$
Table I. Continued.

D, Cluster 4

\begin{tabular}{lc}
\hline Gene & Degree \\
\hline NRP1 & 6 \\
CXCR4 & 5 \\
HDAC9 & 5 \\
SCG2 & 4 \\
CHGB & 4 \\
\hline
\end{tabular}

\section{Discussion}

The present study identified significant DEGs in a neuroblastoma cell line with CDK2 silencing, including $M D M 2, C D K 1$, PSMD14 and TSPO. The genes with higher degrees in the PPI network were significantly enriched in the p53 signaling pathway, cell cycle and proteasome.

MDM2 with the highest connectivity degrees in Cluster 1 was significantly upregulated in the neuroblastoma samples. The MDM2 gene encodes a nuclear-localized E3 ubiquitin ligase, which is a critical effector of the $M Y C N$ oncogene in tumorigenesis and is a transcriptional target of MYCN in neuroblastoma $(7,22)$. Elevated MDM2 levels increase MYCN-induced genomic instability via regulating centrosome replication in the neuroblastoma (23). In addition, MDM2 may bind to p53 at its transactivation domain with high affinity for negatively modulating its transcriptional activity and stability (24). A previous study favored the idea that the MDM2-p53 interaction was effectively involved in cellular processes via the p53 pathway (25). The p53 signaling pathway and its inactivation has a key regulatory role in neuroblastoma progression (26). Additionally, phosphorylation of $\mathrm{MdmX}$ by $\mathrm{CDK} 2 / \mathrm{Cdc} 2^{\mathrm{p} 34}$ effectively regulates the nuclear export of MDM2, and thus has an important role in the regulation of p53 transcription and stability (27). Inhibition of p53-mediated apoptosis is a prerequisite for $M Y C$-driven tumorigenesis in neuroblastoma (7). This may be the reason behind the upregulated expression of MDM2 in neuroblastoma cells following CDK2 silencing. In the current study, MDM2 was significantly enriched in the p53 signaling pathway. Therefore, the findings of the current study suggest that MDM2 may function as an oncogene for promoting neuroblastoma progression via the p53 signaling pathway, and CDK2 may inhibit $M Y C$-driven tumorigenesis in neuroblastoma by targeting MDM2 and activating the p53 signaling pathway.

PSMD14 is the hub gene in Cluster 3 with the higher degrees. This gene encodes a component of the $26 \mathrm{~S}$ proteasome, which catalyzes the degradation of ubiquitinated intracellular proteins (28). The $26 \mathrm{~S}$ proteasome may mediate the degradation of $\mathrm{N}$-myc in neuroblastoma cells in vivo (29). Increased expression of the proteasome has an important role in the protective effects of sulforaphane against hydrogen peroxide-mediated cytotoxicity in neuroblastoma cells (30). Additionally, a PSMD14 knockdown may restore sensitivity of Mcl1-dependent neuroblastoma to ABT-737 (a small molecule 
Table II. The top 10 enriched GO-biological process terms of cluster genes.

A, Cluster 1

\begin{tabular}{|c|c|c|c|}
\hline ID & Description & Count & P-value \\
\hline GO:0006974 & Response to DNA damage stimulus & 15 & $2.71 \times 10^{-6}$ \\
\hline GO:0048699 & Generation of neurons & 18 & $4.06 \times 10^{-5}$ \\
\hline GO:0009411 & Response to UV & 6 & $2.49 \times 10^{-5}$ \\
\hline GO:0097202 & Activation of cysteine-type endopeptidase activity & 5 & $1.39 \times 10^{-4}$ \\
\hline GO:0051050 & Positive regulation of transport & 11 & $1.40 \times 10^{-4}$ \\
\hline GO:0032270 & Positive regulation of cellular protein metabolic process & 14 & $2.35 \times 10^{-4}$ \\
\hline GO:0007267 & Cell-cell signaling & 16 & $3.86 \times 10^{-4}$ \\
\hline GO:0045937 & Positive regulation of phosphate metabolic process & 11 & $1.30 \times 10^{-3}$ \\
\hline GO:0050877 & Neurological system process & 16 & $1.56 \times 10^{-3}$ \\
\hline GO:0051146 & Striated muscle cell differentiation & 6 & $3.94 \times 10^{-3}$ \\
\hline
\end{tabular}

B, Cluster 2

\begin{tabular}{|c|c|c|c|}
\hline ID & Description & Counts & P-value \\
\hline GO:0007049 & Cell cycle & 231 & 0 \\
\hline GO:0006281 & DNA repair & 81 & 0 \\
\hline GO:0006260 & DNA replication & 72 & 0 \\
\hline GO:0006310 & DNA recombination & 51 & 0 \\
\hline GO:0000082 & G1/S transition of mitotic cell cycle & 41 & 0 \\
\hline GO:0000075 & Cell cycle checkpoint & 38 & 0 \\
\hline GO:0007051 & Spindle organization & 35 & 0 \\
\hline GO:0007126 & Meiosis & 32 & 0 \\
\hline GO:0007088 & Regulation of mitosis & 26 & 0 \\
\hline GO:0000086 & $\mathrm{G} 2 / \mathrm{M}$ transition of mitotic cell cycle & 28 & $2.22 \times 10^{-16}$ \\
\hline
\end{tabular}

C, Cluster 3

\begin{tabular}{|c|c|c|c|}
\hline ID & Description & Count & P-value \\
\hline GO:0002474 & Antigen processing and presentation of peptide antigen via MHC class I & 13 & $3.21 \times 10^{-13}$ \\
\hline GO:0006521 & Regulation of cellular amino acid metabolic process & 11 & $3.08 \times 10^{-13}$ \\
\hline GO:0006977 & $\begin{array}{l}\text { DNA damage response, signal transduction by p53 class mediator resulting } \\
\text { in cell cycle arrest }\end{array}$ & 11 & $1.38 \times 10^{-12}$ \\
\hline GO:0031145 & $\begin{array}{l}\text { Anaphase-promoting complex-dependent proteasomal ubiquitin-dependent } \\
\text { protein catabolic process }\end{array}$ & 11 & $1.88 \times 10^{-11}$ \\
\hline GO:0000209 & Protein polyubiquitination & 14 & $2.32 \times 10^{-11}$ \\
\hline GO:0016071 & mRNA metabolic process & 19 & $1.07 \times 10^{-7}$ \\
\hline GO:0043248 & Proteasome assembly & 3 & $2.04 \times 10^{-5}$ \\
\hline GO:0006406 & mRNA export from nucleus & 4 & $1.35 \times 10^{-3}$ \\
\hline GO:0006369 & Termination of RNA polymerase II transcription & 3 & $4.53 \times 10^{-3}$ \\
\hline GO:0006446 & Regulation of translational initiation & 3 & $1.18 \times 10^{-2}$ \\
\hline
\end{tabular}

D, Cluster 4

\begin{tabular}{|c|c|c|c|}
\hline ID & Description & Count & P-value \\
\hline GO:0007166 & Cell surface receptor signaling pathway & 38 & $1.79 \times 10^{-8}$ \\
\hline GO:0001525 & Angiogenesis & 12 & $2.81 \times 10^{-6}$ \\
\hline GO:0045773 & Positive regulation of axon extension & 4 & $8.88 \times 10^{-6}$ \\
\hline GO:0009968 & Negative regulation of signal transduction & 15 & $3.97 \times 10^{-5}$ \\
\hline
\end{tabular}


Table II. Continued.

D, Cluster 4

\begin{tabular}{llrr}
\hline ID & & \multicolumn{1}{c}{ Description } & Count \\
\hline GO:0006334 & Nucleosome assembly & 6 & $5.21 \times 10^{-5}$ \\
GO:0040013 & Negative regulation of locomotion & 6 & $4.04 \times 10^{-4}$ \\
GO:0001657 & Ureteric bud development & 5 & $4.23 \times 10^{-4}$ \\
GO:0042391 & Regulation of membrane potential & 8 & $5.87 \times 10^{-4}$ \\
GO:0090090 & Negative regulation of canonical Wnt receptor signaling pathway & 4 & $1.60 \times 10^{-3}$ \\
GO:0071495 & Cellular response to endogenous stimulus & 12 & $3.16 \times 10^{-3}$
\end{tabular}

GO, gene ontology.

Table III. Enriched KEGG pathways of cluster genes.

\section{A, Cluster 1}

\begin{tabular}{llrr}
\hline ID & \multicolumn{1}{c}{ Description } & Count & P-value \\
\hline 115 & p53 signaling pathway & 11 & $1.24 \times 10^{-12}$ \\
5200 & Pathways in cancer & 7 & $9.90 \times 10^{-3}$ \\
4510 & Focal adhesion & 5 & $3.48 \times 10^{-3}$ \\
230 & Purine metabolism & 4 & $6.85 \times 10^{-3}$ \\
5214 & Glioma & 4 & $1.33 \times 10^{-3}$ \\
5218 & Melanoma & 4 & $1.85 \times 10^{-3}$ \\
4210 & Apoptosis & 4 & $3.89 \times 10^{-3}$ \\
5215 & Prostate cancer & 4 & $4.22 \times 10^{-3}$ \\
5210 & Colorectal cancer & 3 & $1.09 \times 10^{-2}$ \\
5220 & Chronic myeloid leukemia & 3 & $1.70 \times 10^{-2}$ \\
4512 & ECM-receptor interaction & 3 & $2.53 \times 10^{-2}$ \\
4012 & ErbB signaling pathway & 3 & $2.69 \times 10^{-2}$ \\
240 & Pyrimidine metabolism & 3 & $3.74 \times 10^{-2}$ \\
5219 & Bladder cancer & 2 & $3.91 \times 10^{-2}$ \\
3420 & Nucleotide excision repair & 2 & $4.26 \times 10^{-2}$
\end{tabular}

B, Cluster 2

\begin{tabular}{llrr}
\hline ID & \multicolumn{1}{c}{ Description } & Count & P-value \\
\hline 4110 & Cell cycle & 38 & 0 \\
3030 & DNA replication & 23 & 0 \\
4114 & Oocyte meiosis & 19 & $6.61 \times 10^{-10}$ \\
230 & Purine metabolism & 16 & $2.72 \times 10^{-5}$ \\
240 & Pyrimidine metabolism & 14 & $1.33 \times 10^{-6}$ \\
3430 & Mismatch repair & 11 & $1.44 \times 10^{-11}$ \\
3420 & Nucleotide excision repair & 11 & $4.70 \times 10^{-8}$ \\
4914 & Progesterone-mediated oocyte maturation & 11 & $4.95 \times 10^{-5}$ \\
3410 & Base excision repair & 10 & $2.58 \times 10^{-8}$ \\
3440 & Homologous recombination & 9 & $7.45 \times 10^{-8}$ \\
4115 & p53 signaling pathway & 9 & $1.87 \times 10^{-4}$ \\
3018 & RNA degradation & 6 & $2.01 \times 10^{-2}$ \\
310 & Lysine degradation & 5 & $1.01 \times 10^{-2}$ \\
790 & Folate biosynthesis & 2 & $4.20 \times 10^{-2}$
\end{tabular}


Table III. Continued.

C, Cluster 3

\begin{tabular}{llrr}
\hline ID & \multicolumn{1}{c}{ Description } & Count & P-value \\
\hline 3050 & Proteasome & 10 & $7.56 \times 10^{-12}$ \\
3013 & RNA transport & 6 & $3.52 \times 10^{-3}$ \\
3030 & DNA replication & 3 & $5.19 \times 10^{-3}$ \\
4141 & Protein processing in endoplasmic reticulum & 6 & $5.44 \times 10^{-3}$ \\
3410 & Base excision repair & 2 & $4.17 \times 10^{-2}$ \\
270 & Cysteine and methionine metabolism & 2 & $4.88 \times 10^{-2}$ \\
\hline
\end{tabular}

D, Cluster 4

\begin{tabular}{llll}
\hline ID & \multicolumn{1}{c}{ Description } & Count & P-value \\
\hline 5322 & Systemic lupus erythematosus & 7 & $7.73 \times 10^{-5}$ \\
4144 & Endocytosis & 6 & $4.47 \times 10^{-3}$ \\
4360 & Axon guidance & 5 & $3.16 \times 10^{-3}$ \\
4514 & Cell adhesion molecules (CAMs) & 5 & $3.60 \times 10^{-3}$ \\
5100 & Bacterial invasion of epithelial cells & 3 & $1.71 \times 10^{-2}$ \\
360 & Phenylalanine metabolism & 2 & $7.58 \times 10^{-3}$ \\
260 & Glycine, serine and threonine metabolism & 2 & $2.57 \times 10^{-2}$ \\
350 & Tyrosine metabolism & 2 & $4.06 \times 10^{-2}$ \\
5219 & Bladder cancer & 2 & $4.24 \times 10^{-2}$ \\
\hline
\end{tabular}

KEGG, Kyoto Encyclopedia of Genes and Genomes.

Table IV. The functional annotation of cluster genes in PPI network.

\begin{tabular}{|c|c|c|c|c|}
\hline Cluster no. & $\mathrm{TF}$ & TS genes & Oncogene & Other \\
\hline Cluster 1 & $\begin{array}{l}\text { HAND2, RFX5, HOXD10, } \\
\text { PBX1, ISL1 }\end{array}$ & $\begin{array}{l}\text { CDKN1A, ISG15, TNFRSF10B, } \\
\text { HBP1, YPEL3, FBXW7, BTG2 }\end{array}$ & $\begin{array}{l}\text { IRF2, MDM2, AKT3, } \\
\text { PDGFRB, PBX1 }\end{array}$ & BAX \\
\hline Cluster 2 & $\begin{array}{l}\text { HMGB2, BRCA1, BRIP1, } \\
\text { EZH2, MYBL2, SSRP1, } \\
\text { FOXM1, E2F7, HMGB1, } \\
\text { BRCA2, TEAD1, TAF5, } \\
\text { RBL1, GLI3, GTF2A1, } \\
\text { MYBL1, LHX2 }\end{array}$ & $\begin{array}{l}\text { CHEK1, RBBP7, BRCA1, } \\
\text { BARD1, BLM, FANCD2, } \\
\text { BUB1B, CHEK2, FANCG, } \\
\text { E2F1, LPL, GADD45G, } \\
\text { BRCA2, RBL1, CDK2AP1, } \\
\text { MLH1, ANP32A, LOX, } \\
\text { RBM14, FH, CDKN2C }\end{array}$ & $\begin{array}{l}\text { PTTG1, AURKA, CEP55, } \\
\text { CCNA2, WHSC1, } \\
\text { MYBL2, DEK, HMMR, } \\
\text { CSE1L, RRAS, MYB, } \\
\text { FGFR2, TEAD1, KIT, } \\
\text { NTRK1, MYBL1 }\end{array}$ & $\begin{array}{l}\text { DNMT3B, BUB1, } \\
\text { BIRC5, TACC3, } \\
\text { PLK1, CCNE2, } \\
\text { RAD54B, YEATS4, } \\
\text { ANP32B, ANXA5, } \\
\text { NIF3L1, LHX2 }\end{array}$ \\
\hline Cluster 3 & TFAM, KLF4, ID1 & TIMP3, IGFBP5 & & KLF4 \\
\hline Cluster 4 & SOX9, MEIS1, ETS2 & $\begin{array}{l}\text { SPRY2, LGI1, BAI3, } \\
\text { NRCAM, BLCAP, DUSP6, } \\
\text { PTPRK, SIRT2, PRICKLE1 }\end{array}$ & $\begin{array}{l}\text { VEGFA, RET, MEIS1, } \\
\text { ETS2 }\end{array}$ & SHC1, CBLB \\
\hline
\end{tabular}

$\mathrm{TF}$, transcription factor; TS, tumor suppressor.

inhibitor of $\mathrm{Bcl} 2, \mathrm{BclXL}$ and $\mathrm{BclW}$ ), thus decreasing the activity of $\mathrm{Bcl} 2, \mathrm{BclXL}$ and $\mathrm{BclW}$ (31). Bcl2 family proteins have important roles in neutralizing activated BCL2 like 11 and evading apoptosis in neuroblastoma cells $(32,33)$. Therefore, the findings of the current study suggest that PSMD14 may contribute to neuroblastoma progression via the proteasome. It is of note that the clustering analysis performed in the current study revealed that the expression pattern of genes in Cluster 3 at different time points was evidently opposite to the one observed in Cluster 1. Therefore, it is possible that a synthetic suppression effect occurred between these genes in Cluster 3 and Cluster 1 to some extent. Liang et al (34) demonstrated 
that downregulation of PSMD14 was involved in the activation of p53-regulated pro-apoptotic signaling pathways and the activity of p53 was associated with MDM2 expression (34). Additionally, p53 regulates the expression of cyclin dependent kinase inhibitor $1 \mathrm{~A}$, which mediates the p53-dependent cell cycle arrest at the G1 phase via binding and thus inhibiting the activity of CDK2. Therefore, the findings of the present study also suggest that CDK2 may have a key role in neuroblastoma progression by regulating the expression of p53, which may be due to the synthetically lethal relationship between $M D M 2$ and PSMD14.

CDK1 has an important role in cell cycle regulation by governing the transition from $\mathrm{G} 2$ to $\mathrm{M}$ phase and cell cycle regulation is important for cell proliferation $(35,36)$. The CDK1 inhibitors induce G2 arrest in various cell types and effectively downregulate the expression of $M Y C N$, which in turn reduce the transcriptional activation of $M Y C N$ on the survivin promoter in neuroblastoma cells (37). In the present study, CDK1 was significantly involved in cell cycle. Therefore, CDK1 may be involved in neuroblastoma progression through the cell cycle. However, previous studies have confirmed that CDK1 alone is sufficient to drive the mammalian cell cycle and the genetic ablation of CDK2 may be compensated for by CDK1 $(38,39)$. A previous study determined that despite CDK2 inhibition, the proliferation of cancer cells was due to the expression of CDK1 to some extent (39). In the current study, the expression of CDK1 was downregulated following CDK2 silencing; therefore, it is possible for CDK2 to contribute to neuroblastoma progression via regulation of CDK1 expression.

TSPO is a transmembrane protein associated with the mitochondrial permeability pore, mitochondrial transport has an important role in the initiation of the apoptotic cascade (40). A previous study revealed that TSPO ligands are capable of inducing apoptosis in various types of cancers, such as hepatocellular carcinoma, colorectal cancer, esophageal cancer and glioma (41). TSPO ligand PK11195 induces apoptosis and leads to cell cycle arrest in neuroblastoma cell lines at micromolar concentrations (42). Therefore, TSPO may induce apoptosis in neuroblastoma cells and is involved in cell cycle. However, with CDK2 silencing, the expression of TSPO has been observed to be upregulated. Therefore, $\mathrm{CDK} 2$ may promote neuroblastoma progression by reducing TSPO expression. Due to the effect of synthetic suppression observed between TSPO and CDK1 in the present study, it is possible that CDK2 may be involved in neuroblastoma progression via regulation of the interaction of TSPO and CDK1 in the cell cycle.

However, the relatively small sample size is a limitation of the current study. In addition, there is no experimental evaluation of the present study. Additional experiments, such as expression validation or knockdown assay are required to confirm the current observations.

In conclusion, $M D M 2, C D K 1, P S M D 14$ and $T S P O$ may be key target genes of CDK2, and CDK2 may play an important role in neuroblastoma progression by targeting these genes. MDM2 may function as an oncogene that promotes neuroblastoma tumorigenesis via the p53 signaling pathway. PSMD14 may allow neuroblastoma cells to evade apoptosis in via proteasome. TSPO and CDK1 may be involved in neuroblastoma progression by regulating the cell cycle. CDK 2 may promote neuroblastoma progression by regulating the expression of MDM2, PSMD14, CDK1 and TSPO.

\section{Acknowledgements}

The present study was supported by The Natural Science Foundation of Jilin Province (grant nos. 20150204086SF and 20150101160JC) and The High Technology Research and Development Program of Jilin Province of China (grant nos: 2015Y032-4 and 2014G074).

\section{References}

1. Reck M, Popat S, Reinmuth N, De Ruysscher D, Kerr KM and Peters S; ESMO Guidelines Working Group: Metastatic non-small-cell lung cancer (NSCLC): ESMO clinical practice guidelines for diagnosis, treatment and follow-up. Ann Oncol 3 (Suppl 25): iii27-iii39, 2014.

2. George RE, Sanda T, Hanna M, Fröhling S, Luther W II, Zhang J, Ahn Y, Zhou W, London WB, McGrady P, et al: Activating mutations in ALK provide a therapeutic target in neuroblastoma. Nature 455: 975-978, 2008.

3. Mossé YP, Laudenslager M, Longo L, Cole KA, Wood A Attiyeh EF, Laquaglia MJ, Sennett R, Lynch JE, Perri P, et al: Identification of ALK as a major familial neuroblastoma predisposition gene. Nature 455: 930-935, 2008.

4. George RE, Li S, Medeiros-Nancarrow C, Neuberg D, Marcus K, Shamberger RC, Pulsipher M, Grupp SA and Diller L: High-risk neuroblastoma treated with tandem autologous peripheral-blood stem cell-supported transplantation: Long-term survival update. J Clin Oncol 24: 2891-2896, 2006.

5. Schwab M, Varmus HE, Bishop JM, Grzeschik KH, Naylor SL, Sakaguchi AY, Brodeur G and Trent J: Chromosome localization in normal human cells and neuroblastomas of a gene related to c-myc. Nature 308: 288-291, 1984.

6. Cole MD and Cowling VH: Transcription-independent functions of MYC: Regulation of translation and DNA replication. Nat Rev Mol Cell Biol 9: 810-815, 2008.

7. Slack A, Chen Z, Tonelli R, Pule M, Hunt L, Pession A and Shohet JM: The p53 regulatory gene MDM2 is a direct transcriptional target of MYCN in neuroblastoma. Proc Natl Acad Sci USA 102: 731-736, 2005.

8. Meyer N, Kim SS and Penn LZ: The Oscar-worthy role of Myc in apoptosis. Semin Cancer Biol 16: 275-287, 2006.

9. Molenaar JJ, Ebus ME, Geerts D, Koster J, Lamers F, Valentijn LJ, Westerhout EM, Versteeg R and Caron HN: Inactivation of CDK2 is synthetically lethal to MYCN over-expressing cancer cells. Proc Natl Acad Sci USA 106: 12968-12973, 2009.

10. Vermeulen K, Van Bockstaele DR and Berneman ZN: The cell cycle: A review of regulation, deregulation and therapeutic targets in cancer. Cell Prolif 36: 131-149, 2003.

11. Malumbres M and Barbacid M: Mammalian cyclin-dependent kinases. Trends Biochem Sci 30: 630-641, 2005.

12. Shapiro GI: Cyclin-dependent kinase pathways as targets for cancer treatment. J Clin Oncol 24: 1770-1783, 2006.

13. Hall C, Nelson DM, Ye X, Baker K, DeCaprio JA, Seeholzer S, Lipinski M and Adams PD: HIRA, the human homologue of yeast Hirlp and Hir2p, is a novel cyclin-cdk2 substrate whose expression blocks S-phase progression. Mol Cell Biol 21: 1854-1865, 2001.

14. Irizarry RA, Hobbs B, Collin F, Beazer-Barclay YD, Antonellis KJ, Scherf U and Speed TP: Exploration, normalization, and summaries of high density oligonucleotide array probe level data. Biostatistics 4: 249-264, 2003.

15. Futschik ME and Carlisle B: Noise-robust soft clustering of gene expression time-course data. J Bioinform Comput Biol 3: 965-988, 2005.

16. Kumar L and E Futschik M: Mfuzz: A software package for soft clustering of microarray data. Bioinformation 2: 5-7, 2007.

17. von Mering C, Huynen M, Jaeggi D, Schmidt S, Bork P and Snel B: STRING: A database of predicted functional associations between proteins. Nucleic Acids Res 31: 258-261, 2003.

18. Ashburner M, Ball CA, Blake JA, Botstein D, Butler H, Cherry JM, Davis AP, Dolinski K, Dwight SS, Eppig JT, et al: Gene ontology: Tool for the unification of biology. The gene ontology consortium. Nat Genet 25: 25-29, 2000. 
19. Kanehisa M and Goto S: KEGG: Kyoto encyclopedia of genes and genomes. Nucleic Acids Res 28: 27-30, 2000.

20. Zhao M, Sun J and Zhao Z: TSGene: A web resource for tumor suppressor genes. Nucleic Acids Res 41 (Database Issue): D970-D976, 2013

21. Chen JS, Hung WS, Chan HH, Tsai SJ and Sun HS: In silico identification of oncogenic potential of fyn-related kinase in hepatocellular carcinoma. Bioinformatics 29: 420-427, 2013.

22. Slack A and Shohet JM: MDM2 as a critical effector of the MYCN oncogene in tumorigenesis. Cell Cycle 4: 857-860, 2005

23. Slack AD, Chen Z, Ludwig AD, Hicks J and Shohet JM: MYCN-directed centrosome amplification requires MDM2-mediated suppression of p53 activity in neuroblastoma cells. Cancer Res 67: 2448-2455, 2007.

24. Vassilev LT, Vu BT, Graves B, Carvajal D, Podlaski F, Filipovic Z, Kong N, Kammlott U, Lukacs C, Klein C, et al: In vivo activation of the p53 pathway by small-molecule antagonists of MDM2. Science 303: 844-848, 2004

25. Meek DW and Knippschild U: Posttranslational modification of MDM2. Mol Cancer Res 1: 1017-1026, 2003

26. Tweddle DA, Pearson AD, Haber M, Norris MD, Xue C, Flemming $\mathrm{C}$ and Lunec J: The p53 pathway and its inactivation in neuroblastoma. Cancer Lett 197: 93-98, 2003.

27. Elias B, Laine A and Ronai Z: Phosphorylation of MdmX by $\mathrm{CDK} 2 / \mathrm{Cdc} 2(\mathrm{p} 34)$ is required for nuclear export of $\mathrm{Mdm} 2$. Oncogene 24: 2574-2579, 2005.

28. Tanaka K: The proteasome: Overview of structure and functions Proc Jpn Acad Ser B Phys Biol Sci 85: 12-36, 2009.

29. Bonvini P, Nguyen P, Trepel J and Neckers LM: In vivo degradation of N-myc in neuroblastoma cells is mediated by the $26 \mathrm{~S}$ proteasome. Oncogene 16: 1131-1139, 1998.

30. Kwak MK, Cho JM, Huang B, Shin S and Kensler TW: Role of increased expression of the proteasome in the protective effects of sulforaphane against hydrogen peroxide-mediated cytotoxicity in murine neuroblastoma cells. Free Radic Biol Med 43: 809-817, 2007.

31. Laetsch T, Liu X, Vu A, Sliozberg M, Vido M, Elci OU, Goldsmith KC and Hogarty MD: Multiple components of the spliceosome regulate Mcl1 activity in neuroblastoma. Cell Death Dis 5: e1072, 2014.

32. Goldsmith KC, Lestini BJ, Gross M, Ip L, Bhumbla A, Zhang X, Zhao H, Liu X and Hogarty MD: BH3 response profiles from neuroblastoma mitochondria predict activity of small molecule Bcl-2 family antagonists. Cell Death Differ 17: 872-882, 2010.
33. Goldsmith KC, Gross M, Peirce S, Luyindula D, Liu X, Vu A Sliozberg M, Guo R, Zhao H, Reynolds CP and Hogarty MD: Mitochondrial Bcl-2 family dynamics define therapy response and resistance in neuroblastoma. Cancer Res 72: 2565-2577, 2012.

34. Liang J, Parchaliuk D, Medina S, Sorensen G, Landry L, Huang S, Wang M, Kong Q and Booth SA: Activation of p53-regulated pro-apoptotic signaling pathways in PrP-mediated myopathy. BMC Genomics 10: 201, 2009.

35. Goga A, Yang D, Tward AD, Morgan DO and Bishop JM: Inhibition of CDK1 as a potential therapy for tumors over-expressing MYC. Nat Med 13: 820-827, 2007.

36. Bettayeb K, Oumata N, Echalier A, Ferandin Y, Endicott JA, Galons H and Meijer L: CR8, a potent and selective, roscovitine-derived inhibitor of cyclin-dependent kinases. Oncogene 27: 5797-5807, 2008.

37. Chen Y, Tsai YH and Tseng SH: Inhibition of cyclin-dependent kinase 1-induced cell death in neuroblastoma cells through the microRNA-34a-MYCN-survivin pathway. Surgery 153: 4-16, 2013.

38. Santamaría D, Barrière $C$, Cerqueira $A$, Hunt S, Tardy C, Newton K, Cáceres JF, Dubus P, Malumbres M and Barbacid M: Cdk1 is sufficient to drive the mammalian cell cycle. Nature 448: 811-815, 2007.

39. Tetsu O and McCormick F: Proliferation of cancer cells despite CDK2 inhibition. Cancer Cell 3: 233-245, 2003.

40. Casellas P, Galiegue S and Basile AS: Peripheral benzodiazepine receptors and mitochondrial function. Neurochem Int 40: 475-486, 2002

41. Santidrián AF, Cosialls AM, Coll-Mulet L, Iglesias-Serret D, de Frias M, González-Gironès DM, Campàs C, Domingo A, Pons G and Gil J: The potential anticancer agent PK11195 induces apoptosis irrespective of p53 and ATM status in chronic lymphocytic leukemia cells. Haematologica 92: 1631-1638, 2007.

42. Mendonca-Torres MC and Roberts SS: The translocator protein (TSPO) ligand PK11195 induces apoptosis and cell cycle arrest and sensitizes to chemotherapy treatment in pre- and post-relapse neuroblastoma cell lines. Cancer Biol Ther 14: 319-326, 2013. 